\title{
FORMAÇÃO DO PROFESSOR INCLUSIVO À LUZ DA TEORIA Histórico-Cultural: UMA ANÁliSE da SUA PRODUÇÃo ACADÊMICA (2008-2018)
}

\author{
INCLUSIVE TEACHER EDUCATION IN THE LIGHT OF HISTORICAL-CULTURAL \\ THEORY: AN ANALYSIS OF HIS ACADEMIC PRODUCTION (2008-2018)
}

\begin{abstract}
Márcia Mendes de Lima Mestre em Ciências Ambientais pela Universidade Federal de Rondônia - UNIR; professora do Ensino Básico, Técnico e Tecnológico do IFRO - Campus Ariquemes. Ariquemes, RO - BR. marcia.lima@ifro.edu.br
\end{abstract}

\begin{abstract}
Luciana Aparecida de Araújo
Pós-doutorado pela Fundação Carlos Chagas. Doutora em Educação pela Universidade Estadual Paulista Júlio de Mesquita Filho, UNESP. Docente do Programa de Pós-Graduação em Educação pela FFC Unesp Campus Marília e do curso de Pedagogia da FFC Unesp, Marília. Docente e chefe do Departamento de Didática FFC, Marilia. Marília, SP - BR. luciana.penitente@unesp.br

(D) Claudia Aparecida Prates
\end{abstract} Mestre em Educação Escolar pela Universidade Federal de Rondônia - UNIR, pedagoga do Ensino Básico, Técnico e Tecnológico do IFRO Campus Vilhena. Vilhena, RO - BR. claudia.prates@ifro.edu.br

(D) Mauro Sérgio Demício Mestre em Letras pela Universidade Federal de Rondônia - UNIR, professor do Ensino Básico, Técnico e Tecnológico do IFRO Campus São Miguel do Guaporé. Líder do Grupo de Pesquisa LINAHC (Linguagens, Artes e Humanidades em Educação na Contemporaneidade) - IFRO e membro do Grupo de Pesquisa Organizações e Democracia/UNESP. São Miguel do Guaporé, RO - BR.

mauro.demicio@ifro.edu.br

Resumo: As discussões em torno da formação de professores a partir da perspectiva da educação inclusiva têm se intensificado nos últimos anos entre os pesquisadores, perspectivados pela ideia de promover uma educação de qualidade que garanta ao aluno público-alvo da Educação Especial o seu acesso e permanência nas escolas brasileiras. Com isso em vista, o presente artigo visa abordar a educação inclusiva à luz da Teoria Histórico-Cultural ao pensar a formação docente na perspectiva da educação inclusiva e contextualizá-la a partir da construção do conhecimento dos professores sobre esse processo. Assim, delineou-se como objetivo deste artigo compreender e identificar como as produções acadêmicas têm abordado a formação do professor para a inclusão à luz da teoria Histórico-Cultural, no período entre 2008 e 2018 . Para esse fim, realizou-se uma revisão bibliográfica e mapeamento das teses e dissertações depositadas na Biblioteca Digital de Teses e Dissertações (BDTD) entre os anos 2008 e 2018. Espera-se contribuir com as discussões em torno da formação docente para a inclusão escolar, considerando a importância da reflexão sobre os aspectos culturais, sociais e as vivências pessoais no processo de formação da identidade profissional docente.

Palavras-chave: Educação. Formação de professores. Inclusão escolar. Teoria Histórico-Cultural. Produção acadêmica.

Abstract: Discussions around teacher education from an Inclusive Education perspective have intensified in recent years among researchers, envisioned by the idea of promoting quality education, which guarantees access to the student, the target audience of Special Education and permanence in Brazilian schools. In this perspective, this chapter aims to approach Inclusive Education in the light of the Historical-Cultural Theory when thinking about teacher education from the perspective of inclusive education and contextualizing it from the construction of teachers' knowledge about this process. Thus, the objective of this chapter was to understand and identify how academic productions have approached teacher education for Inclusion in the light of Historical Cultural theory, in the corresponding period between (2008-2018). To this end, a bibliographic review and mapping of the theses and dissertations deposited in the Digital Library of Theses and Dissertations (BDTD) between the years 2008 - 2018 was carried out. It is hoped that this article may contribute to the discussions around teacher education for school inclusion, considering the importance of reflecting on cultural, social aspects and personal experiences in the process of forming the teaching professional identity.

Keywords: Education. Teacher training. School inclusion. Historical-Cultural theory. Academic production.

\section{Para citar - ABNT NBR 6023:2018}

LIMA, Márcia Mendes de; ARAÚJO, Luciana Aparecida de; PRATES, Claudia Aparecida; DEMÍCIO, Mauro Sérgio. Formação do professor inclusivo à luz da Teoria Histórico-Cultural: uma análise da sua produção acadêmica (2008-2018). Cadernos de Pósgraduação, São Paulo, v. 19, n. 2, p. 15-32, jul./dez. 2020. Disponível em: https://doi.org/10.5585/cpg.v19n2.16774. 


\section{Introdução}

A educação numa perspectiva inclusiva tem sido pauta de discussões e recorrentes reflexões acadêmicas, bem como tem ganhado destaque no meio acadêmico (DÍAZ et al., 2009; POKER et al., 2016). Percebe-se que essa discussão tem se ampliado e a cada ano caminha no sentido de fortalecer o debate em torno de uma educação igualitária e de qualidade, que compreenda o ato de ensino-aprendizagem além da prática de ensinar os conteúdos escolares, mas que prepare o aluno para conviver com as diferenças, dando novos sentidos à educação inclusiva.

A educação numa perspectiva inclusiva constitui um paradigma educacional baseado na concepção de direitos humanos, em que a igualdade e as diferenças são vistas como valores indissociáveis, e que, de acordo com o contexto histórico, avança em relação à ideia de equidade dentro e fora do ambiente escolar. Com o intuito anunciado de buscar uma educação de qualidade, temse intensificado os meios para garantir o acesso e a permanência dos alunos com deficiência nas escolas brasileiras. Nesse sentido, compreender as políticas públicas de educação inclusiva em documentos legais se torna relevante quando se espera identificar os avanços e recuos presentes no sistema educativo (MOURA; CANAN, 2012).

Segundo Matiskei (2004), os termos inclusão e exclusão fazem parte da mesma realidade educacional. Dessa forma, discutir mecanismos para viabilizar a inclusão social, econômica, digital, cultural ou escolar significa considerar a lógica excludente presente nos atuais modos de organização e produção social. Nesse contexto, cabe ao poder público a tarefa e a responsabilidade de buscar novos caminhos para a superação de entraves presentes na sociedade que distanciam do acesso aos bens e serviços os segmentos excluídos, e, no caso específico da inclusão escolar, do direito à educação (MATISKEI, 2004).

Existem leis consolidadas que garantem o direito à educação de qualidade para alunos público-alvo da Educação Especial no ensino regular, como a Política Nacional de Educação Inclusiva, instituída por meio da Lei $n^{\circ}$ 6.571/2008, que estabeleceu a obrigatoriedade de a escola de ensino regular promover a educação para todos os alunos, sem discriminação. Anterior à lei de 2008, a Lei no 9394/96 (LDB) já resguardava o direito de toda criança com necessidades educativas especiais frequentar as escolas regulares (BRASIL, 1999).

A Política Nacional da Educação Especial (BRASIL, 2008b) propõe ações educacionais que superem a lógica da exclusão no âmbito escolar e na sociedade como um todo. Para que isso ocorra, essa política anuncia a garantia de matrícula de todos os alunos, sem exceções, no sistema regular de ensino, visando com isso assegurar também aos alunos com necessidades educacionais especiais as condições adequadas para uma educação igualitária nos vários níveis de ensino. 
Para tanto, as escolas precisam adaptar-se para que possam atender às necessidades educacionais desses alunos, público-alvo da Educação Especial (BRASIL, 2008a), e, para que isso ocorra, é necessário que se rompa com as práticas excludentes que ocorrem nas instituições escolares, sendo a formação docente (inicial e continuada) ferramenta fundamental nesse processo, sobretudo por possibilitar aos docentes oportunidades de reflexão acerca de seu papel de incluir pessoas e promover aprendizagem.

De acordo com Escórcio (2008), é necessário:

[...] um processo que busque remover as barreiras impostas pela exclusão em seu sentido mais amplo, visando à proposição de alternativas que não se destinem apenas a um grupo restrito de pessoas, mas ao campo social mais amplo. Sendo a escola constitutiva desse contexto social, os desdobramentos e transformações ocorridas na sociedade refletirão sem dúvida na escola. (ESCÓRCIO, 2008, p. 23).

Dessa forma, ao refletir sobre formação de professores inclusivos é importante compreender primeiro o que é educação inclusiva, pois não se refere apenas a conceitos, caracteriza-se como todas as formas e possibilidades de compreensão e respeito às diversidades existentes. Nesse sentido, European (2012) nos diz que:

A educação inclusiva é um conceito amplo com impacto sobre as políticas para os ensinos obrigatório e superior e para a formação de professores. Os objetivos da educação inclusiva são alcançados em contextos e sistemas que valorizem todos de igual forma e que vêm as escolas como recursos da comunidade. A educação inclusiva preocupa-se com todos os alunos e visa aumentar a participação significativa de um indivíduo na aprendizagem, reduzindo a sua exclusão da educação e da sociedade em geral. (EUROPEAN, 2012, p. 27).

A questão da educação inclusiva não se esgota nela mesma, mas implica outras dimensões como a inserção e o acolhimento do aluno pela escola, família e pela sociedade. De acordo com Marchesi (2004, p. 20), “Os problemas de aprendizagem dos alunos são determinados, em grande medida, por seu ambiente familiar e social e pelas características da própria escola."

Nessa perspectiva, Vygotsky (1997) afirma que a criança deficiente não sente diretamente sua deficiência, mas percebe as dificuldades que resultam dela e, com isso, acaba por sentir-se numa posição social inferior. Dessa forma, a família e a escola devem estar atentas aos vínculos pessoais estabelecidos, que devem proporcionar à criança confiança em suas potencialidades e condições de superação.

Vygotsky (1997) defende a não segregação dos alunos com necessidades especiais, visto que as interações sociais entre grupos heterogêneos são condições fundamentais para o desenvolvimento do pensamento e da linguagem. 
Seguindo esse pensamento, à luz da Teoria Histórico-Cultural desenvolvida por Vygotsky, é que se pensa a educação inclusiva neste artigo. Para o autor, a aprendizagem promove o desenvolvimento, tendo o professor como o mediador entre o aluno e o conhecimento, proporcionado por meio de um conteúdo social e historicamente acumulado, sendo assim sistematizado.

A partir dessa premissa da Teoria Histórico-Cultural, surge uma indagação importante ao pensar a formação docente na perspectiva da educação inclusiva e contextualizá-la a partir da construção do conhecimento dos professores sobre esse processo, a saber: o que apontam as produções acadêmicas sobre a formação do professor para a inclusão à luz da Teoria Histórico-Cultural? Acredita-se que tal reflexão se faz necessária, uma vez que o discurso da inclusão está presente no cotidiano das instituições escolares.

A partir desse questionamento, delineou-se como objetivo deste artigo compreender e identificar como as produções acadêmicas têm abordado a formação do professor para a inclusão à luz da Teoria Histórico-Cultural, no período entre 2008 e 2018.

\section{O caminho metodológico}

Para a realização deste texto, foram selecionados como aportes os pressupostos metodológicos apontados por Bogdan e Biklen (1994) e Bardin (2016). Realizou-se uma revisão bibliográfica e, baseando-se na sistematização apresentada por Lüdke e André (1986), selecionou-se teses e dissertações depositadas na Biblioteca Digital de Teses e Dissertações (BDTD) entre os anos 20082018. A escolha do recorte temporal (2008-2018) justifica-se pelo fato de 2008 ser um marco com a publicação da Lei n ${ }^{\circ}$ 6.571/2008, que discute sobre a Política Nacional de Educação Inclusiva (BRASIL, 2008b).

Ademais, optou-se pela Biblioteca Digital de Teses e Dissertações (BDTD) por se apresentar como um banco de dados de grande abrangência e reconhecimento pela comunidade acadêmica científica, além de ser uma base que favorece o trabalho do pesquisador, dada a facilidade de acesso e de manuseio aos materiais nela disponibilizados.

O processo de busca pelas teses e dissertações ocorreu mediante seleção de palavras-chave, de modo que essas pudessem favorecer o acesso às teses e dissertações relacionadas à temática proposta. Após algumas tentativas de acesso aos materiais a partir de diferentes palavras-chave, as buscas foram filtradas com base nas seguintes: "Formação de professores inclusivos" e "Teoria Histórico-Cultural”.

Foram excluídas as teses e dissertações que possuíam temática que não apresentava ou não tratava como sujeito o público-alvo dessa revisão, além das pesquisas replicadas (CARDOSO, 2018). 
Os procedimentos de análise dos materiais encontrados foram realizados a partir da análise de conteúdo, assim como proposto por Bardin (2016). O material encontrado foi organizado e sistematizado mediante a construção de instrumento de pesquisa considerando os seguintes aspectos: referências das pesquisas, objetivos, tipo de abordagem, metodologia, resultados principais e conclusões.

A partir da organização, sistematização e análise do material com base na elaboração de um instrumento de pesquisa, foi possível identificar as principais tendências encontradas nas pesquisas produzidas entre os anos de 2008 e 2018 sobre a Teoria Histórico-Cultural e a formação do professor inclusivo.

\section{Principais resultados e discussões}

A busca inicial deu-se a partir da palavra-chave "Formação de professores inclusivos", encontrando na base de dados um total de 714 trabalhos, divididos em 178 teses e 536 dissertações, que tratavam de diversos aspectos da formação do professor para a educação inclusiva, segundo abordagens teóricas diversas, abordando aspectos legais da formação, processos de ensino e aprendizagem, entre outros, muitos não relacionados com a Teoria Histórico-Cultural e a formação do professor inclusivo.

Inseriu-se na segunda tentativa o termo "Teoria Histórico-Cultural”, formando o descritor "Formação de professores inclusivos" $A N D$ "Teoria Histórico-Cultural”, retornando um total de 35 trabalhos; desses, 08 teses e 27 dissertações. A pré-análise dos resumos foi realizada e verificouse que a busca apresentou a temática pretendida.

Após leitura prévia dos resumos dos trabalhos, que foram realizados em 18 instituições diferentes, foram selecionados um total de 07 textos, sendo 05 dissertações e 02 teses, para compor o escopo de mapeamento, pois apresentavam a temática proposta para a análise. Esses trabalhos agruparam os principais tópicos encontrados nas buscas sobre contribuições da Teoria HistóricoCultural na formação do professor inclusivo, trabalhos que apresentavam estreita relação com o objetivo proposto para este estudo.

Após a leitura dos resumos, as teses e dissertações foram sistematizadas por meio de três eixos de análise (BARDIN, 2016), a saber: "Formação da identidade profissional docente", "Formação inicial e continuada docente" e "Políticas institucionais na formação de professores inclusivos". 


\section{Eixo: "Formação da identidade profissional docente"}

O eixo "Formação da identidade profissional docente" é composto por 02 dissertações de mestrado que trazem reflexões sobre trajetória da formação da identidade profissional do professor inclusivo, baseando-se na construção do conhecimento e de sua reflexão.

Iniciou-se pelo trabalho de Siems (2008), que em sua dissertação de mestrado intitulada "A construção da identidade profissional do professor da educação especial em tempos de educação inclusiva” buscou compreender como se constitui a identidade de professoras que são referência de conhecimento acerca da educação de pessoas com deficiência, os chamados "professores da Educação Especial”. A autora utilizou como perspectiva de reflexão teórico-metodológica a Teoria Histórico-Cultural e, para análise, os aportes de Bakhtin e sua Teoria Enunciativa da Linguagem; e Vygotsky, com a Teoria da Construção Social do Conhecimento.

Nos resultados encontrados, os históricos de vida pessoal, acadêmica e profissional destacam-se na constituição da identidade profissional, que também é afetada pela organização do trabalho docente. Assim, cada professor se relaciona com a diferença e pode assumir atitudes diversas, dependendo do grau de sua compreensão e aceitação da diferença como elemento a ser social e culturalmente incorporado, e também da conscientização que pode levá-lo a tomar o múltiplo como elemento de enriquecimento da coletividade (SIEMS, 2008).

A dissertação de Siems (2008) traz uma reflexão acerca do lugar ocupado na atualidade pela Educação Especial, entendida como modalidade específica em nosso sistema educacional, concluindo que ela ainda se encontra excluída das discussões que se estabelecem no ensino regular.

Segundo Mello e Lugle (2014), na Teoria Histórico-Cultural a aprendizagem é o motor do desenvolvimento e esse não ocorre espontaneamente, os processos exigem participações ativas do sujeito com os "produtos da cultura", assim o desenvolvimento não é linear, mas se dá como um "complexo processo dialético", com inúmeras influências externas, do meio e da vivência que são essenciais no desenvolvimento do sujeito.

Essas discussões remetem ao olhar crítico na formação de professores, em especial para a educação inclusiva, numa perspectiva de formação de uma identidade docente única, enriquecida pelas experiências socioculturais e vivenciadas durante o processo de formação.

O segundo texto analisado, Lima (2010), trata-se da dissertação de mestrado intitulada "Não ser, eis a questão. A constituição da identidade do professor inclusivo" e teve como objetivo traçar algumas reflexões sobre a constituição da identidade de professores inclusivos e seus processos formativos socioculturais. A pesquisa utilizou-se da abordagem qualitativa e sua metodologia consistiu em pesquisa bibliográfica, com análise dialética dos dados. 
A análise de Lima (2010) evidencia que as condições objetivas de transformação são impossíveis, pois somente a valorização dos sujeitos e a sua tomada de consciência farão com que a educação seja realizada com ética. Destaca-se na dissertação o movimento de educação inclusiva, considerando-o como tentativa de uma parcela da sociedade em promover mudanças. Conclui que é necessário provocar a reflexão e a crítica para que se possa ultrapassar as ideias e processos de reificação ${ }^{1}$ e a educação inclusiva avance os limites, seja ousada e reviva a aptidão e a vocação de educar.

Para Mello e Lugle (2014, p. 267) "a experiência individual também é fundamental para apropriação da experiência cultural, mas não é o suficiente". As autoras destacam que o sujeito, ao relacionar-se com o outro que possui maior experiência com "o objeto ou fenômeno da cultura", ele (o sujeito), pela vivência, compreende sua função, apropriando-se do que está sendo estudado.

Sendo assim, na formação de professores, o aprendizado não se constitui somente da observação, mas o fazer-se professor será determinado também pelas experiências socioculturais anteriores e pela vivência em sala de aula.

Assim, as reflexões presentes nas dissertações corroboram as ideias de Vygotsky (1997), especialmente no que concerne à sua ideia de que nas relações sociais e na interação do ser com o meio sociocultural é que o sujeito se constitui, demarcando, assim, a importância da linguagem para o desenvolvimento e aperfeiçoamento dos meios de trabalho. É nesse processo contínuo que o sujeito, por meio do trabalho, das relações sociais, culturais e históricas, constitui sua identidade.

\section{Eixo: "Formação inicial e continuada docente"}

O eixo "Formação inicial e continuada docente" é composto por 01 tese de doutorado e 02 dissertações de mestrado que trazem ponderações sobre os processos de formação inicial e continuada docente para a atuação na educação inclusiva, abordando desde o percurso de formação inicial às estratégias de formação continuada in loco.

$\mathrm{Na}$ análise dos estudos, fica evidente o pensamento de Vygotsky (1997 quando esse autor afirma que os seres humanos se constituem a partir das relações que estabelecem com o ambiente e com os outros. Dessa forma, compreende-se que os processos formativos do docente são constituídos coletivamente e na esfera cultural, pela interação. Nesse sentido, a formação inicial e continuada do professor ocorre a partir de seus contextos históricos e das marcas de seu tempo e espaço: 
É muito ingênuo interpretar o social apenas como coletivo, como existência de uma multiplicidade de pessoas. O social existe até onde há apenas um homem e as suas emoções pessoais. Por isso, quando a arte realiza a catarse e arrasta para esse fogo purificador as comoções mais íntimas e mais vitalmente importantes de uma alma individual, o seu efeito é um efeito social. A questão não se dá da maneira como representa a teoria do contágio, segundo a qual o sentimento que nasce em um indivíduo contagia a todos, torna-se social; ocorre exatamente o contrário. A refundição das emoções fora de nós realiza-se por força de um sentimento social que foi objetivado, levado para fora de nós, materializado e fixado nos objetos externos de arte, que se tornaram instrumento da sociedade. (VYGOTSKI, 1997, p. 315).

Nesse contexto, Vygotsky (1997) traz contribuições significativas que possibilitam compreender a formação inicial e continuada do professor de modo mais integrado, abrangendo amplas relações entre as experiências vividas e os saberes que os docentes elaboram.

O primeiro trabalho analisado neste eixo é a tese de Brabo (2013), com o título: "Formação docente inicial e o ensino ao aluno com deficiência em classe comum na perspectiva da educação inclusiva". Seu principal objetivo é a análise do percurso da formação docente inicial, tomando como base a disciplina Intervenção Pedagógica e Necessidades Educativas Especiais, ofertadas pela Faculdade de Educação - FACED/UFRGS, com a perspectiva para o ensino/atendimento do aluno com deficiência em classe comum na universidade brasileira.

Brabo (2013) utilizou uma abordagem qualitativa na pesquisa. Em sua metodologia, delimitou o contexto que se configurou nas instalações da UFRGS e na FACED, e, como atores do corpus investigativo, reuniu três grupos: ex-alunos da disciplina Intervenção Pedagógica e Necessidades Educativas Especiais, dos semestres 2009.2, 2010.1 e 2010.2; e coordenadores dos cursos de licenciatura da UFRGS, no total de 17 profissionais. Como instrumentos metodológicos foram utilizados análise de documentos; entrevista semiestruturada; experiência pessoal; e diário de campo, e, como aportes teóricos, Basil Bernstein e Lev Seminovich Vygotsky, com sua Teoria Histórico-Cultural.

Em seus resultados, Brabo (2013) teve a percepção de avanços discretos na atuação educacional para desenvolver ações que propiciem o acesso e a permanência de alunos com deficiência em seus cursos. Relata também que poucas ações incrementam a formação docente para a demanda dos futuros professores que trabalharão com alunos com deficiência em classes comuns das escolas regulares, denotando discreta ampliação de projetos de pesquisa e extensão que considerem esse campo de conhecimento.

Brabo (2013), em conclusão, enfatiza o papel da disciplina Intervenção Pedagógica e Necessidades Educativas Especiais, sendo esse um espaço de mediação entre alunos, professores e a prática pedagógica. Outro fator importante é a interdisciplinaridade, com uma visão de fomentar a criação de culturas inclusivas, de contribuição na produção de políticas inclusivas e do desenvolvi- 
mento de práticas inclusivas, sendo que a universidade brasileira deve se tornar um locus de formação para a inclusão, levando à transformação social, e que o professor seja o autor de seu discurso pedagógico.

Somente ao longo do processo formativo o futuro docente atribui sentidos pessoais e cria apropriações de significados sociais pelos objetos culturais, uma organização proposital para que o processo se viabilize, assim torna-se autor de um discurso próprio, elaborado a partir das suas experiências socioculturais e suas significações.

O termo significação é apontado na Teoria Histórico-Cultural como fator importante do processo, este representará a síntese de práticas sociais e culturais para o contexto formativo, o aprender a ser professor.

Segundo Leontiev (1978, p. 94):

\begin{abstract}
A significação é aquilo que num objeto ou fenômeno se descobre objetivamente num sistema de ligações, de interações e de relações objetivas. A significação é refletida e fixada na linguagem, o que lhe confere a sua estabilidade. Sob a forma de significações linguísticas, constitui o conteúdo da consciência entrando no conteúdo da consciência social, torna-se assim a "consciência real" dos indivíduos, objetivando em si o sentido subjetivo que o refletido tem para eles.
\end{abstract}

Leontiev (1983) denota que não é possível ensinar o sentido de algo, pois o sentido será atribuído pelo sujeito a partir de suas experiências e no decorrer da atividade proposta, sendo que o processo não é automático, exige uma vivência e reflexão sobre os movimentos internos do sujeito, assim atribuiria a cada docente um discurso pedagógico único, forjado pelas vivências e significações ímpares que se formaram dos contatos durante todo o processo de formação do sujeito.

As demais pesquisas encontradas no eixo tratam de formação continuada. Oliveira (2017), em sua dissertação intitulada: "Formação continuada para atuação pedagógica inclusiva na educação infantil: um estudo no sistema municipal de ensino de Belém - Pará”, investigou o processo de formação continuada de professores da Educação Infantil do sistema municipal de ensino de Belém - Pará, com vistas à inclusão de crianças com deficiência. Para tal fim, utilizou a pesquisa empírica de orientação teórico-metodológica Histórico-Cultural, inspirada nos aportes teóricos de Vygotsky e de colaboradores.

Para a realização de sua pesquisa, Oliveira (2017), determinou duas etapas distintas: a caracterização da dinâmica do processo de formação continuada ofertada pelo Centro de Referência em Inclusão Educacional Gabriel Lima Mendes (CRIE) aos professores de Educação Infantil, por 
meio de registros de informações, análises de documentos e aplicação de questionários; e a investigação da dinâmica do assessoramento. As informações foram coletadas por meio de observações e entrevistas, sendo analisadas sob o enfoque Histórico-Cultural.

Em seus resultados, Oliveira (2017) observou que as formações continuadas convergem para ações pontuais, com temas específicos da Educação Especial e com pouca articulação com as outras disciplinas ou com a educação como um todo. Outro fator importante apontado é a necessidade de formação e de assessoramento regular para os docentes que atuam com a inclusão, que os assuntos se relacionem com a realidade do docente, além da importância da participação de todos os docentes nas formações, independente de trabalharem ou não com alunos com deficiências. Conclui que a mudança começa com a implantação e efetivação de políticas públicas de formação continuada, de forma que os processos formativos realmente contribuam para a formação de fato do professor, visando ao processo de inclusão escolar.

Seguindo essa vertente, o processo de formação de professores necessita criar condições para que os conhecimentos sejam apropriados e para que haja compreensão de seus significados, em especial na inclusão escolar, principalmente formando sujeitos (professores) que visualizem que seu trabalho não significa ensinar algo que a criança com deficiência não tenha capacidade de aprender, mas "inserir o ato de ensino nas relações mútuas entre as possibilidades e limites que se põem de manifesto no desempenho da criança, limites que, uma vez superados, avançam em forma de novas possibilidades" (VYGOTSKY, 2001a, p. 223), e assim entender as limitações, superar e avançar com novas possibilidades para o ensino.

Ainda neste eixo, Sudré (2008), em sua dissertação de mestrado intitulada “O ensino-aprendizagem de alunos surdos no ensino médio em classe de ensino regular", investiga os recursos utilizados pelo professor na interação com os alunos quando ele não possui conhecimento regular de LIBRAS e não é auxiliado por intérpretes. Em termos de metodologia, o autor faz uso do método interpretativo crítico, por meio de roteiro com perguntas norteadoras. Após a interpretação dos dados, a análise foi agrupada em quatro temas: ensino-aprendizagem, inclusão-exclusão, surdo e linguagem, seguindo os aportes teóricos de Bronckart e à luz da Teoria Histórico-Cultural, sendo a base de discussão dos dados os estudos de Bakhtin, Vygotsky e de Skliar. O local de realização do estudo foi uma escola pública estadual de Ensino Fundamental e Médio de uma cidade da grande São Paulo, e os sujeitos foram 03 alunos surdos, 03 professores e os demais alunos da turma. Os dados foram coletados entre 2007 e 2008 utilizando-se dos seguintes instrumentos: gravação de duas aulas em áudio e vídeo; gravação em áudio de entrevistas; observações e notas de campo. 
As discussões suscitadas por Sudré (2008) permitiram ponderar sobre o real processo de inclusão do aluno surdo na escola regular. O autor observa que a escola inclusiva ainda nega condições para o desenvolvimento pleno dos alunos com deficiência. Afirma que para se adentrar na real inclusão faz-se necessário reestruturar a escola brasileira, para que ela contemple as demandas, tanto sociais como culturais e políticas, das minorias.

Assim, partindo dos pressupostos da Teoria Histórico-Cultural, é na interação com o outro e com o meio que o sujeito aprende e desenvolve habilidades, sendo a escola, nesse sentido, capaz de tornar-se um ambiente primordial de inclusão dos alunos com deficiência, constituindo-se numa “chave dos processos de humanização" (MELLO; LUGLE, 2014), isso apoiado na formação de professores que reconheçam a educação como peça-chave para a reestruturação da inclusão, no intuito da "produção da humanização nas novas gerações" (MELLO; LUGLE, 2014).

O aluno com deficiência não pode deixar de ter acesso a essa interação com a heterogenia do ambiente escolar, para que possa levá-lo, por meio da mediação dos professores, a ter confiança e desenvolver suas potencialidades e condições de superação.

A partir das discussões propostas no eixo "Formação inicial e continuada docente" os estudos de Vygotsky (2006) levam à compreensão de que o processo de aprendizagem acontece sempre em forma de colaboração entre as pessoas. Nesse sentido, é necessário, ao pensar docência e formação inicial e continuada numa perspectiva de inclusão, que a dimensão coletiva seja um elemento propulsor de práticas pedagógicas inclusivas, constituindo, dessa forma, o professor inclusivo.

\section{Eixo: "Políticas Institucionais para a formação de professores inclusivos"}

Neste eixo, "Políticas Institucionais para formação de professores inclusivos", foram relacionadas 01 tese de doutorado e 01 dissertação de mestrado que apresentam os aspectos políticos da formação de professores para a Educação Especial e os aspectos institucionais que tentam responder à perspectiva da educação inclusiva nos cursos de formação de professores.

Lara (2017), em sua tese intitulada "Professor na área da Deficiência Intelectual: análise da formação na perspectiva docente" analisou a política de formação dos professores em Educação Especial na área da Deficiência Intelectual do município de São Paulo. Para a realização da pesquisa fora utilizada a análise documental da proposta curricular do curso, além de aplicação de questionários com os professores que lecionaram na Educação Especial. Após as análises, evidenciou-se no discurso dos professores formados a responsabilidade que carregam de ancorar a inclusão, mesmo tendo recebido formação categorial na área da Deficiência Intelectual. Nesse sentido, a 
formação não será capaz de suprir a necessidade de incentivos para a produção e organização de recursos pedagógicos para a inclusão escolar.

Em suas considerações, Lara (2017) ponderou que os professores devem se apoiar em uma sólida formação continuada, servindo de suporte para as transformações graduais de suas práticas pedagógicas, enraizadas nas escolas em novas práticas e recursos, para atender um novo público, de forma a motivar uma verdadeira educação inclusiva.

Vygotsky (2001b) nos apresenta um olhar sobre os processos formativos dos sujeitos, com extensa análise sobre a formação dos processos psicológicos superiores, com contribuições expressivas permitindo compreender a formação de professores de modo integrador, assim abrangendo a relação entre as experiências vividas e os saberes que os docentes elaboram.

Para Prezotto et al. (2015), o professor, quando entra em sala de aula, tem diversas representações de escola, aluno e de docência, colocando-o em posição histórica e socialmente construída. O mesmo ocorre quando há a presença de alunos com deficiência, "reconhecer este contexto culturalmente diverso é compreender a singularidade de formar-se.” (PREZOTTO et al., 2015)

As transformações nas práticas pedagógicas para favorecer a inclusão nas escolas se darão num processo contínuo, em que o sujeito (professor), por meio de uma constante formação continuada, estabelece através da cultura as relações que conduzem ao ensino-aprendizagem, bem como aos contratos sociais entre os sujeitos envolvidos no processo.

Ainda no contexto de políticas voltadas para formação de professores, Ribeiro (2011), em sua dissertação intitulada "Formação de professores de ciências e educação inclusiva em uma instituição de ensino superior em Jataí-Go”, investiga se as políticas internas da instituição de ensino superior em que pesquisou (IES/Jataî) contemplam a perspectiva da educação inclusiva em seus cursos de formação de professores, assim como para receber estudantes com deficiência. Para a realização da pesquisa foi elencado como método o estudo de caso nos cursos de licenciatura em biologia, física, matemática e química, com abordagem qualitativa e, como instrumentos metodológicos, a aplicação de questionários, realização de entrevistas e análise dos projetos pedagógicos dos cursos. Os dados foram analisados a partir da Análise de Conteúdo e análise qualitativa.

Ribeiro (2011) conclui que, embora uma grande parcela dos docentes se mostre receptiva às propostas da educação inclusiva, eles não se sentem preparados para atuar e formar para as diversidades encontradas nas salas de aula, ressaltando a importância das pesquisas em educação, da necessidade de uma boa formação inicial e continuada, além de denunciar que os cursos analisados não proporcionam nenhum tipo de formação para a diversidade e a inclusão. 
As políticas de formação de professores para a inclusão devem ser capazes de promover o aprendizado, na medida em que o sujeito seja capaz de internalizar experiências culturais, atribuindo a elas um novo contexto e significado (PREZOTTO et al., 2015).

Partimos assim do pressuposto de que as pesquisas analisadas no eixo "Políticas institucionais na formação de professores inclusivos" possibilitaram refletir sobre educação inclusiva enquanto processo em construção contínua, permeada por um movimento dialético de avanços e retrocessos em práticas pedagógicas, sobretudo com relação à formação de professores. E nesse movimento dialético do caráter histórico do processo educativo é que se pode afirmar que a formação continuada na perspectiva da educação inclusiva não vem com um manual com sequências didáticas e indicações de o que fazer e como o docente tem que atuar. (ALVES, 2012)

\section{Considerações finais}

Após a análise das pesquisas que têm por aporte a Teoria Histórico-Cultural na formação docente para a inclusão escolar, baseando-se nos debates apresentados, é possível apontar um panorama para a questão da formação inicial e continuada do professor para a inclusão. Essa temática se apresenta nas discussões dos autores como a mais debatida, bem como a preocupação com a trajetória de formação da identidade profissional do professor inclusivo, que é tema recorrente nas dissertações e teses encontradas.

Outro aspecto relevante encontrado é a escassez de pesquisas que discutem o tema. Mesmo com os descritores amplos como "Formação de professores inclusivos" e "Teoria Histórico-Cultural", poucas pesquisas retornaram, embora sejam termos importantes para o processo de efetivação da educação inclusiva.

A pesquisa agrupou três grandes eixos de análise: "Formação da identidade profissional docente", "Formação inicial e continuada docente" e "Políticas institucionais na formação de professores inclusivos". O primeiro é norteado pelas reflexões da trajetória da formação da identidade profissional do professor inclusivo na construção de seu conhecimento e de sua reflexão, ficando evidente nos apontamentos que somente o reconhecimento de todos os sujeitos do processo e de sua conquista de consciência podem provocar as mudanças necessárias para a reflexão crítica e ressignificação dos processos de inclusão escolar.

Outro fator importante abordado é a reflexão sobre as experiências sociais e pessoais, elas se destacam na formação da identidade profissional docente, sendo também afetadas pelo ambiente profissional no qual o sujeito está inserido.

Assim, as discussões do eixo corroboram a Teoria Histórico-Cultural no sentido de que o aprendizado não se constitui somente da observação, mas o fazer-se professor será determinado 
também pelas experiências socioculturais anteriores e pela vivência em sala de aula. A experiência individual é fundamental para a apropriação da experiência cultural, mas a relação com atores mais experientes cria relações sociais e interações que constituem o sujeito, em um processo contínuo, por meio do trabalho, das relações sociais, culturais e históricas, na constituição de uma identidade docente.

No eixo de formação inicial e continuada docente, os autores apresentam considerações sobre os processos de formação inicial e continuada do docente para educação inclusiva. Para a formação inicial, a percepção evidenciada é a de que os avanços são discretos nas ações para assegurar o acesso e a permanência de alunos com deficiência em cursos superiores, e que poucas ações são desenvolvidas na formação inicial docente com o fim de prepará-los para atuar na inclusão dos alunos com deficiência nas escolas regulares.

Outro fator relevante apontado é que o professor deve ser o autor de seu próprio discurso pedagógico, fomentado pela prática da interdisciplinaridade e pela criação de culturas inclusivas, devendo ainda contribuir para a elaboração de políticas públicas efetivas, sendo a universidade brasileira um locus de formação para a inclusão e dessa forma induzindo a transformação social.

A formação continuada docente atua de forma diferente, por meio de ações pontuais, com temas específicos relacionados à Educação Especial e à interdisciplinaridade. O entendimento é de que a formação para a inclusão é uma necessidade constante e regular para todos os docentes, independente de atuarem ou não com a inclusão, e deve contextualizar-se com a realidade do docente.

Partindo da apreciação das pesquisas, olhamos para a perspectiva de Vygotsky e compreendemos os processos formativos do docente como constituídos coletivamente, na esfera cultural, na interação entre as experiências vividas e os saberes que os docentes elaboram. Assim, ao longo da formação, o futuro docente atribui sentidos pessoais e cria apropriações de significados sociais pelos objetos culturais tornando-se autor de um discurso próprio, a partir das suas experiências socioculturais e suas significações.

A síntese de práticas sociais e culturais para o contexto formativo docente, o aprender a "ser professor", sua vivência e reflexão sobre os movimentos internos atribuirão a cada docente um discurso pedagógico único, tecido nas experiências e significações ímpares a que tiveram contato durante todo o processo de formação e de atuação.

É nessa interação com o outro e com o meio que o professor aprende e desenvolve habilidades humanizadoras, e a escola torna-se um ambiente primordial de inclusão dos alunos com deficiência, sendo uma chave dos processos de humanização. 
No último eixo, o de políticas institucionais na formação de professores inclusivos, foram discutidos pelos autores os aspectos políticos institucionais da formação de professores que tentam responder à perspectiva da educação inclusiva. Os trabalhos apontam que os docentes não se sentem preparados para atuar e formar para a diversidade, mesmo que se mostrem receptivos às propostas da educação inclusiva, pois os cursos de licenciaturas, em sua grande maioria, não proporcionam formação para a diversidade e inclusão.

Ainda sobre os processos formativos, as pesquisas refletem que somente a implementação e efetivação de políticas públicas de formação continuada que incluam a reestruturação da escola brasileira para contemplar os processos, tanto sociais, culturais e políticos das minorias, poderia levar a um avanço rumo à inclusão escolar.

Nesse eixo, apoiados em Vygotsky, olhamos para processos formativos dos sujeitos compreendendo a formação de modo integrador, de forma a abranger a relação entre as experiências vividas e os saberes que os docentes elaboram, ou seja, um processo integrado e contínuo.

As transformações nas práticas pedagógica que tem como meta favorecer a inclusão nas escolas devem ser um processo contínuo, em que o sujeito (professor), por meio de uma constante formação, estabeleça por meio da cultura as relações de ensino e aprendizado, bem como os contratos sociais entre todos os sujeitos envolvidos no processo. Somente políticas de formação efetivas de professores para a inclusão devem ser capazes de promover tais mudanças.

Os resultados apresentados demonstraram lacunas apontadas pelos autores das pesquisas selecionadas referentes à formação docente, assim como são insuficientes as políticas públicas voltadas para a efetivação da inclusão escolar. Dessa forma, novas pesquisas devem ser realizadas para preencher tais lacunas.

Por fim, espera-se com esse artigo contribuir com as discussões em torno da formação docente para a inclusão escolar, considerando a importância da reflexão sobre os aspectos pessoais e sociais no processo de formação da identidade profissional docente.

\footnotetext{
Notas

${ }^{1}$ No dicionário Houaiss reificação é um termo filosófico, segundo Georg Lukács (1885-1971), que teve seu conceito ampliado por Karl Marx, sendo um "processo histórico inerente às sociedades capitalistas, caracterizado por uma transformação experimentada pela atividade produtiva, pelas relações sociais e pela própria subjetividade humana, sujeitadas e identificadas cada vez mais ao caráter inanimado, quantitativo e automático dos objetos ou mercadorias circulantes no mercado. Sinônimos: alienação e coisificação".
}

\section{Referências}

ALVES, L. M. A. A formação continuada de professores para uma escola inclusiva à luz do Materialismo Histórico-Dialético. In: OLIVEIRA, Ivanilde O. (et. al.). Epistemologia e Educação: Reflexões sobre temas educacionais. Belém: PPGED-UEPA, 2012. 
BARDIN, L. Análise de conteúdo. São Paulo: Edições 70, 2016.

BOGDAN, R.; BLIKEN, S. K. Investigação qualitativa em educação, uma introdução à teoria e aos métodos. Tradução: Maria João Álvares, Sara Bahia dos Santos, Telmo Mourinho Baptista. Porto: Porto Editora, 1994.

BRABO, G. M. B. Formação docente inicial e o ensino ao aluno com deficiência em classe comum na perspectiva da educaşão inclusiva. Tese (Doutorado) Universidade Federal do Rio Grande do Sul. Faculdade de Educação. Programa de Pós-Graduação em Educação. 2013. Disponível em: http://bdtd.ibict.br/vufind/Search/Results?filter $\% 5 \mathrm{~B} \% 5 \mathrm{D}=$ publishDate $\% 3 \mathrm{~A} \% 22 \% 5 \mathrm{~B} 2008+\mathrm{TO}+2018 \% 5 \mathrm{D} \% 22 \&$ join $=\mathrm{AND} \&$ bool $\%$ \% $\%$ \% $5 \mathrm{D}=\mathrm{AND} \&$ lookfor $\% 5 \mathrm{~B} \% 5 \mathrm{D}=$ forma $\% \mathrm{C} 3 \% \mathrm{~A} 7 \% \mathrm{C} 3 \% \mathrm{~A} 3 \mathrm{o}+\mathrm{de}+$ professores + inclusivos\&lookfor $0 \% 5 \mathrm{~B} \% 5 \mathrm{D}=$ Teoria + Hist $\% \mathrm{C} 3 \% \mathrm{~B} 3$ rico + Cultural\&type $\% 5 \mathrm{~B} \% 5 \mathrm{D}=\mathrm{AllFi}$ elds\&type $\%$ 5B $\% 5 \mathrm{D}=$ AllFields\&page $=2$. Acesso abr. de 2019.

BRASIL. LDB: Lei de Diretrizes e Bases da Educação Nacional, nº 9394/96. Apresentação: Esther Grossi. 2. ed. Rio de Janeiro: DP\&A, 1999.

BRASIL. Ministério da Educação e Cultura. Secretaria Geral. Centro Nacional de Educação Especial. Plano Nacional de Educação Especial. 2008a.

BRASIL. Política Nacional de Educação Especial na Perspectiva da Educação Inclusiva. Brasília: MEC/SEESP, 2008b.

CARDOSO, P. P. C. Formação continuada de professores: um estudo a partir das abordagens teórica, normativa e prática. (2018). Dissertação (Mestrado em Educação) Faculdade de Filosofia e Ciências, UNESP - Marília, 2018.

DÍAZ, F.; BORDAS, M.; GALVÃO, N.; MIRANDA, T.; Educação inclusiva, deficiência e contexto social: questões contemporâneas/, organizadores; autores, Elias Souza dos Santos, et al. Salvador: EDUFBA, 354p. 2009.

ESCÓRCIO, D.C.M. A interação entre professor e aluno com deficiência intelectual em escola inclusiva: um estudo de caso. (2008). Dissertação (Mestrado em Educação) - Centro de Ciências da Educação, Universidade Federal do Piauí, Teresina, 2008 Disponível em: http://www.europeanagency.org/sites/default/files/te4i-profile-of-inclusiveteachers_Profile-of-Inclusive-TeachersPT.pdf. Acesso em jun. de 2018.

EUROPEAN. Formação de professores para a inclusão perfil de professores inclusivos. Formação de Professores para a Inclusão - Agência Europeia para o Desenvolvimento da Educação Especial. 2012. Disponível em: 12 http://www.european-agency.org/sites/default/files/te4i-profile-of-inclusiveteachers_Profile-of-Inclusive-Teachers-PT.pdf. Acesso em jun. de 2018.

LARA, P. T. Professor na área da deficiência Intelectual: análise da formação na perspectiva docente. Tese (Doutorado em Educação) - Universidade Estadual Paulista (Unesp). Marília, 2017. Disponível em: http://bdtd.ibict.br/vufind/Search/Results?filter $\% 5 \mathrm{~B} \% 5 \mathrm{D}=$ publis-

$\mathrm{hDate} \% 3 \mathrm{~A} \% 22 \% 5 \mathrm{~B} 2008+\mathrm{TO}+2018 \% 5 \mathrm{D} \% 22 \& j$ in $=\mathrm{AND} \& b o o 10 \% 5 \mathrm{~B} \% 5 \mathrm{D}=\mathrm{AND} \&$ look- 
for $0 \% 5 \mathrm{~B} \% 5 \mathrm{D}=$ forma $\% \mathrm{C} 3 \% \mathrm{~A} 7 \% \mathrm{C} 3 \% \mathrm{~A} 3 \mathrm{o}+\mathrm{de}+$ professores + inclusivos\&lookfor $\% 5 \mathrm{~B} \% 5 \mathrm{D}=$ Teoria + Hist $\% \mathrm{C} 3 \% \mathrm{~B} 3$ rico + Cultural\&type $0 \% 5 \mathrm{~B} \% 5 \mathrm{D}=\mathrm{AllFi}$ elds\&type $\% 5 \mathrm{~B} \% 5 \mathrm{D}=$ AllFields\&page $=2$. Acesso abr. de 2019.

LEONTIEV, A. O homem e a cultura. O Desenvolvimento do Psiquismo. Ed. Horizonte Universitário, 1978.

LEONTIEV, A. N., Actividad, consciência e personalidad. Buenos Aires: Ciências del Hombre, 1983. Disponível: https://www.marxists.org/portugues/leontiev/1978/activ_person/index.htm (Versão traduzida) Acesso: 25 de mai. de 2019

LIMA, C. C. S. Não ser, eis a questão. A constituição da identidade do professor inclusivo. Dissertação (Mestrado em Educação) - Faculdade de Educação, Universidade de São Paulo, São Paulo. 2010. Disponível em: http://bdtd.ibict.br/vufind/Search/Results?filter $\% 5 \mathrm{~B} \% 5 \mathrm{D}=$ publishDate $\% 3 \mathrm{~A} \% 22 \% 5 \mathrm{~B} 2008+\mathrm{TO}+2018 \% 5 \mathrm{D} \% 22 \& j$ in $=\mathrm{AND} \&$ bool $\%$ \% $\mathrm{B} \% 5 \mathrm{D}=\mathrm{AND} \& l o o k-$ for $0 \% 5 \mathrm{~B} \% 5 \mathrm{D}=$ forma $\% \mathrm{C} 3 \% \mathrm{~A} 7 \% \mathrm{C} 3 \% \mathrm{~A} 3 \mathrm{o}+\mathrm{de}+$ professores + inclusivos\&lookfor $05 \mathrm{~B} \% 5 \mathrm{D}=$ Teoria + Hist $\% \mathrm{C} 3 \% \mathrm{~B} 3$ rico + Cultural\&type $\% 5 \mathrm{~B} \% 5 \mathrm{D}=\mathrm{AllFi}$ elds\&type $0 \% 5 \mathrm{~B} \% 5 \mathrm{D}=$ AllFields\&page $=2$. Acesso abr. de 2019.

LÜDKE, M; ANDRÉ, M. E. D. A. Pesquisa em Educação: abordagens qualitativas. 5 ed. São Paulo: EPU, 1986.

MARCHESI, Á. Da linguagem da deficiência às escolas inclusivas. In: COLL, C.; MARCHES I, Á.; PALACIOS, J.; (org.). Desenvolvimento psicológico e educação. Trad. Fátima Murad, Porto Alegre: Artmed, 2004. Disponível em: http://srvd.grupoa.com.br/uploads/imagensExtra/legado/C/ COLL_Cesar/Desenvolvimento_Psicologico_Educacao_Vol3_2Ed/Liberado/Cap_01.pdf Acesso em abr. de 2019 .

MATISKEI, A. C. R. M. Políticas públicas de inclusão educacional: desafios e perspectivas. Educar em Revista. Curitiba, PR: Ed. UFPR, n.23, 2004. p. 185-202. Disponível em: http://www.scielo.br/scielo.php?pid=S0104-40602004000100012\&script=sci_abstract\&tlng=pt. Acesso em abr. de 2019.

MELLO, S. A.; LUGLE, Andreia Maria Cavaminami. Formação de Professores: Implicações Pedagógicas da Teoria Histórico-Cultural. Revista Contrapontos, v. 14, n. 2, p. 259-274, 2014.

MOURA, E. B.; CANAN, R. S. Políticas Públicas Educação Inclusiva: Avanços e receios a partir de documentos legais. ANPEDSUL. 2012. p.15. Disponível em: http://www.ucs.br/etc/conferencias/index.php/anpedsul/9anpedsul/paper/viewFile/173/181. Acesso em abr. de 2019 .

OLIVEIRA, M. de F. de. Formação continuada para atuação pedagógica inclusiva na educação infantil: um estudo no sistema municipal de ensino de Belém - Pará. Dissertação (Mestrado em Educação) Universidade Federal do Pará, Instituto de Ciências da Educação, Belém, Programa de Pós-Graduação em Educação. 2017.Disponível em: http://bdtd.ibict.br/vufind/Search/Results?filter $\% 5 \mathrm{~B} \% 5 \mathrm{D}=$ publishDate $\% 3 \mathrm{~A} \% 22 \% 5 \mathrm{~B} 2008+\mathrm{TO}+2018 \% 5 \mathrm{D} \% 22 \&$ join $=$ AND\&bool $\%$ \% $\mathrm{B} \% 5 \mathrm{D}=\mathrm{AND} \&$ lookfor $0 \% 5 \mathrm{~B} \% 5 \mathrm{D}=$ forma $\% \mathrm{C} 3 \% \mathrm{~A} 7 \% \mathrm{C} 3 \% \mathrm{~A} 3 \mathrm{o}+\mathrm{de}+$ professores + inclusivos\&lookfor $0 \% 5 \mathrm{~B} \% 5 \mathrm{D}=$ Teoria + Hist $\% \mathrm{C} 3 \% \mathrm{~B} 3$ rico + Cultural\&type $\% \% 5 \mathrm{~B} \% 5 \mathrm{D}=\mathrm{AllFi}$ elds\&type0\%5B\%5D=AllFields\&page $=2$. Acesso abr. de 2019. 
POKER, R. B.; MARTINS S. E. S. de O.; GIROTO, C. R. M.; Educação inclusiva: em foco a formação de professores / organizadores. - São Paulo: Cultura Acadêmica; Marília: Oficina Universitária, 2016.

PREZOTTO, M.; FERREIRA, L. H.; ARAGÃO, A. M. F. de. Sobre águas e meninos: formação de professores numa perspectiva histórico-cultural. Laplage em Revista, [S.1.], v. 1, n. 3, p. p.20-33, dez. 2015. ISSN 2446-6220. Disponível em: http://www.laplageemrevista.ufscar.br/index.php/lpg/article/view/98. Acesso em: 26 jun. p.20-33. 2019.

RIBEIRO, E. B. V. Formação de professores de ciências e educação inclusiva em uma instituição de ensino superior em Jataí-Go. Dissertação (Mestrado em Matemática) - Universidade Federal de Goiás, Goiânia, 2011. Disponível em: http://bdtd.ibict.br/vufind/Search/Results?filter $\% 5 \mathrm{~B} \% 5 \mathrm{D}=$ publishDate $\% 3 \mathrm{~A} \% 22 \% 5 \mathrm{~B} 2008+\mathrm{TO}+2018 \% 5 \mathrm{D} \% 22 \& j$ in $=\mathrm{AND} \& b o o 10 \% 5 \mathrm{~B} \% 5 \mathrm{D}=\mathrm{AND} \& l o o k-$ for $0 \% 5 \mathrm{~B} \% 5 \mathrm{D}=$ forma $\% \mathrm{C} 3 \% \mathrm{~A} 7 \% \mathrm{C} 3 \% \mathrm{~A} 3 \mathrm{o}+\mathrm{de}+$ professores +inclusivos\&lookfor $\% 5 \mathrm{~B} \% 5 \mathrm{D}=$ Teoria + Hist $\% \mathrm{C} 3 \% \mathrm{~B} 3$ rico + Cultural\&type $\% 5 \mathrm{~B} \% 5 \mathrm{D}=\mathrm{AllFi}$ elds\&type $0 \% 5 \mathrm{~B} \% 5 \mathrm{D}=$ AllFields\&page $=2$. Acesso abr. de 2019.

SIEMS, M. E. R. A construção da identidade profissional do professor da educação especial em tempos de educação inclusiva. Dissertação (Mestrado em Educação) -Universidade Federal de Juiz de Fora (UFJF) 2008.Disponível em: http://bdtd.ibict.br/vufind/Search/Results?filter $\% 5 \mathrm{~B} \% 5 \mathrm{D}=$ publis$\mathrm{hDate} \% 3 \mathrm{~A} \% 22 \% 5 \mathrm{~B} 2008+\mathrm{TO}+2018 \% 5 \mathrm{D} \% 22 \&$ join $=\mathrm{AND} \&$ bool $\% \% 5 \mathrm{~B} \% 5 \mathrm{D}=\mathrm{AND} \&$ lookfor $0 \% 5 \mathrm{~B} \% 5 \mathrm{D}=$ forma $\% \mathrm{C} 3 \% \mathrm{~A} 7 \% \mathrm{C} 3 \% \mathrm{~A} 3 \mathrm{o}+\mathrm{de}+$ professores + inclusivos\&lookfor $0 \% 5 \mathrm{~B} \% 5 \mathrm{D}=$ Teoria + Hist $\% \mathrm{C} 3 \% \mathrm{~B} 3$ rico + Cultural\&type $0 \% 5 \mathrm{~B} \% 5 \mathrm{D}=\mathrm{AllFi}-$ elds\&type $\% 5 \mathrm{~B} \% 5 \mathrm{D}=$ AllFields\&page $=2$. Acesso abr. de 2019.

SUDRÉ, E. C. O ensino-aprendizagem de alunos surdos no ensino médio em classe de ensino regular. Dissertação (Mestrado em Linguística) - Pontifícia Universidade Católica de São Paulo, São Paulo, 2008.Disponível em: http://bdtd.ibict.br/vufind/Search/Results?filter $\% 5 \mathrm{~B} \% 5 \mathrm{D}=$ publishDate $\% 3 \mathrm{~A} \% 22 \% 5 \mathrm{~B} 2008+\mathrm{TO}+2018 \% 5 \mathrm{D} \% 22 \& j$ in $=\mathrm{AND} \&$ bool $\% \% 5 \mathrm{~B} \% 5 \mathrm{D}=\mathrm{AND} \&$ lookfor $0 \% 5 \mathrm{~B} \% 5 \mathrm{D}=$ forma $\% \mathrm{C} 3 \% \mathrm{~A} 7 \% \mathrm{C} 3 \% \mathrm{~A} 3 \mathrm{o}+\mathrm{de}+$ professores + inclusivos\&lookfor $0 \% 5 \mathrm{~B} \% 5 \mathrm{D}=$ Teoria + Hist $\% \mathrm{C} 3 \% \mathrm{~B} 3$ rico + Cultural\&type $0 \% 5 \mathrm{~B} \% 5 \mathrm{D}=\mathrm{AllFi}$ elds\&type $0 \% 5 \mathrm{~B} \% 5 \mathrm{D}=$ AllFields\&page $=2$. Acesso em: 2 abr. 2019.

VYGOTSKY, L. S. A formação social da mente. São Paulo: Martins Fontes, 1998.

VYGOTSKY, L. S. Obras completas. Tomo cinco: Fundamentos de Defectologia. 5. ed. Havana: Editorial Pueblo Y Educación, 1997.

VYGOTSKY, L. S. Aprendizagem e Desenvolvimento Intelectual na Idade Escolar. In: VYGOTSKY, L. S.; LURIA, A.R.; LEONTIEV, A.N. Linguagem, Desenvolvimento e Aprendizagem. São Paulo: Ícone Editora LTDA, 2001a.

VYGOTSKI, L. S. A construção do Pensamento e da Linguagem. São Paulo: Martins Fontes, 2001b. Disponível em: https://edisciplinas.usp.br/pluginfile.php/2477794/mod_resource/content $/ 1 / \mathrm{A} \% 20$ construcao $\% 20 \mathrm{do} \% 20$ pensamento $\% 20 \mathrm{e} \% 20 \mathrm{da} \% 20$ linguagem.pdf. Acesso 26 mai. de 2019

VYGOTSKY, L. S. Obras Escogidas. Vol IV. Madrid: Visor, parte 2, 2006. Disponível em https://kupdf.net/download/Vygotsky-obras-escogidas-tomo-

5_58df0312dc0d60023d8970e8_pdf. Acesso em abr. de 2019. 